\title{
Pressure reduction in plunge pools by triangular wedges at high-head overfall spillways
}

Jun Deng PhD

Professor, State Key Laboratory of Hydraulic and Mountain River Engineering, Sichuan University, Chengdu, China

\section{Wangru Wei PhD}

Assistant Professor, State Key Laboratory of Hydraulic and Mountain Rive Engineering, Sichuan University, Chengdu, China (corresponding author: weiwangru@scu.edu.cn.)

\author{
Hongfeng Duan MSc \\ Engineer, State Key Laboratory of Hydraulic and Mountain River \\ Engineering, Sichuan University, Chengdu, China
}

Overfall spillways are important hydraulic structures for the release of overtopping water flows downstream of a dam. To reduce the effects of the impact of falling water in plunge pools, an overfall spillway outlet design that produces a longitudinally spreading jet is required. This study examined the effects of a triangular wedge placed at the end of an overfall spillway to deflect the water flow in the lateral direction, making the jet longitudinally diffuse before reaching the plunge pool. Laboratory data on the mean pressure coefficient were used to analyse the effects of various design parameters. An increase in the deflection ratio and a decrease in the weir crest length reduced the jet impact pressure. Compared with the impact of a rectangular jet falling into a plunge pool, an appropriate triangular wedge structure was found to improve the spreading of the impingement jet and reduce the mean dynamic pressure coefficient. By optimising the geometric design to accomplish jet impact control, the results of the present investigation may help engineers to design overfall spillways in high-head dam projects.

\section{Notation}

\section{$B \quad$ channel width}

$B_{\mathrm{j}} \quad$ thickness of jet

$b \quad$ outlet width

$b_{\mathrm{d}} \quad$ bottom width of triangular wedge

C turbulence parameter

$C_{\mathrm{p}} \quad$ mean dynamic pressure coefficient

Fr Froude number

$\mathrm{Fr}_{\mathrm{j}} \quad$ Froude number at entrance

g gravitational acceleration

$H \quad$ vertical distance between weir crest of overfall spillway and water surface in plunge pool

$H_{0} \quad$ falling height

$h \quad$ water head

$h_{\mathrm{d}} \quad$ height of triangular wedge

$L_{\mathrm{b}} \quad$ jet break-up length

$L_{\mathrm{d}} \quad$ length of triangular wedge

$p_{\mathrm{m}} \quad$ maximum time-mean pressure

$Q_{\mathrm{w}} \quad$ water discharge rate

$q \quad$ flow discharge per unit width

Re Reynolds number

We Weber number

$Y \quad$ tailwater depth

$\alpha \quad$ bottom angle of spillway

$\rho \quad$ water density

$\sigma \quad$ surface tension between air and water

$\phi \quad$ coefficient determined by basic flow conditions

\section{Introduction}

In recent decades, technological advances in hydraulics have promoted the development of high-head dams. One of the most important aspects of dam protection is the transfer of reservoir water downstream. The overfall spillway on a highhead arch dam is a key hydraulic structure, releasing overtopping water flows into a plunge pool, as shown in Figure 1. The overfall spillway is used as the flood discharge structure in many high-arch dams (reaching 200-300 m), such as Jinping-I dam (China, $305 \mathrm{~m}$ high), Xiaowan dam (China, $292 \mathrm{~m}$ ), Xiluodu dam (China, $285.5 \mathrm{~m}$ high) and Ertan dam (China, $240 \mathrm{~m})$. High-velocity plunging jets $(40-50 \mathrm{~m} / \mathrm{s})$ transfer water from the reservoir level to the plunge pool downstream, generating high demand on hydraulic structures. Overfall spillways have received considerable attention due to their massive energy dissipation and potential for failure during large flood discharge operations.

For the release of large volumes of water from an overfall spillway, the main principle of outlet design is to ensure spreading of the impingement jet as this improves the jet aeration and decreases the discharge per unit width as it enters the pool downstream (Castillo, 2006; Castillo et al., 2015; Ervine et al., 1997). Both aspects are influenced by the outlet type because the initial jet shape determines the basic spreading properties. A general comparison of circular and rectangular jets in terms of the impact on the pool bottom indicates that there are significant differences in the dynamic pressure when other conditions are identical (Beltaos and Rajaratnam, 1973; 

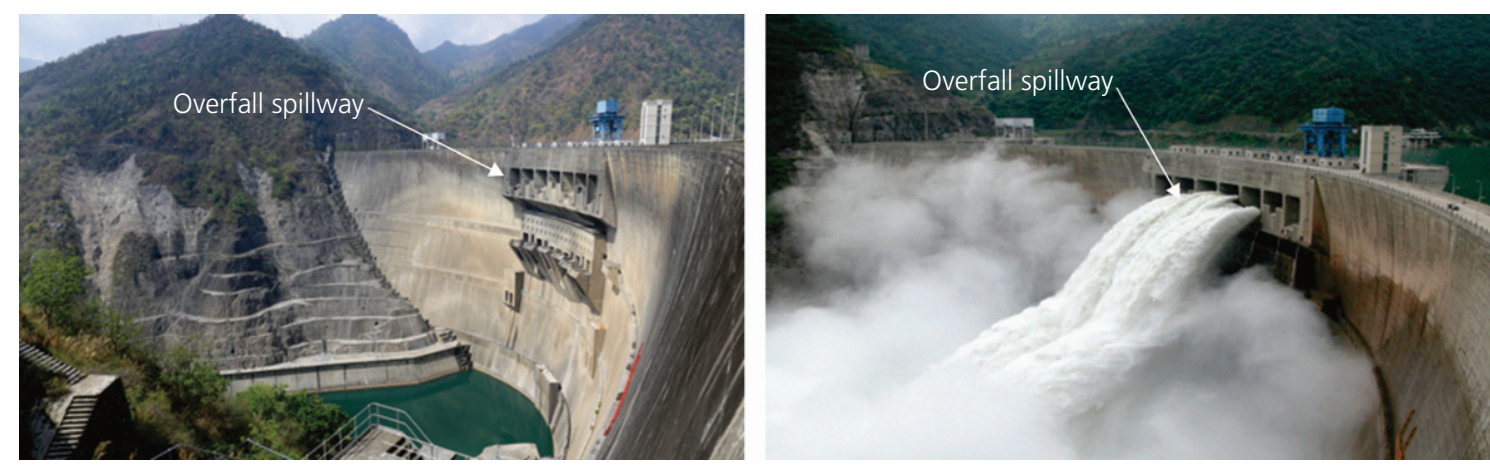

Figure 1. Overfall spillway releasing water at Ertan dam, China

Cola, 1965; Franzetti and Tanda, 1987). Recent studies on ski-jump flows have emphasised that an effective deflection design at the spillway outlet contributes to jet aeration and fractioning during the spreading process in the air (Deng et al., 2018; Pfister and Hager, 2012; Pfister et al., 2014; Schmocker et al., 2008; Teng and Yang, 2018). However, because the dam is relatively thin and the channel is short, the flow pattern from the overfall spillway mainly consists of the falling jet and so the water flow velocity at the outlet is relatively insignificant in terms of bottom deflection applications (Juon and Hager, 2000; Steiner et al., 2008; Yang et al., 2019). Moreover, the lateral space for water discharge and energy dissipation is limited because high-head dams are usually built in narrow valleys. Regular lateral-contraction deflection is rarely used because of the flow choking limitation (Li et al., 2012; Wu et al., 2012). It is thus vital to use an effective outlet design that satisfies the requirements of water-release operations and energy dissipation.

Assessments of jet impacts are usually a technical component of the outlet structure design (Castillo, 2007; Pardo-Bosch and Aguado, 2015). Therefore, designers require information on the magnitude of the impact pressure, the jet properties and the optimised design principles of the outlet geometry parameters (Puertas and Dolz, 2005). According to structural safety considerations, different theoretical analyses and empirical predictions have been proposed to characterise the development and impact process of a falling jet (Beltaos, 1976; Puertas, 1994). Key parameters - including the jet break-up length, the jet spreading thickness, turbulence intensity and relative cushion depth - have been used to identify the physical process. However, it is difficult to obtain a practical and general model of a falling jet due to different experimental facilities and measurements, complicated surface tension, turbulent effects and uncertainties associated with the entrainment of air into the jet (Bollaert and Schleiss, 2003a).

A triangular wedge design was proposed for the outlet of an overfall spillway on Jinping-I dam (305 m high with a $235 \mathrm{~m}$ water head), satisfying both the high-head and longitudinal jet diffusion requirements. Preliminary studies on the overfall spillway at this dam compared the jet pattern with the triangular wedge deflector to that without a triangular wedge (Figure 2). The water flow close to the sidewall was found to be deflected and lifted by the triangular wedge, leading to a laterally thin and longitudinally diffuse jet being released from the overfall spillway. The increased diffusion of the flow surface in the air and the decreased unit discharge at the entrance of the plunge pool were found to reduce the jet impact pressure on the pool floor and improve the energy dissipation. For a plunge pool with a given water depth, the maximum mean impact pressure on the bottom can be reduced from $229.32 \mathrm{kPa}$ without a triangular wedge to $50.47 \mathrm{kPa}$ with a triangular wedge. In this paper, based on a series of experimental tests, the effects of design parameters on the mean dynamic pressure coefficient of a plunging jet are analysed. The optimal design of the overfall spillway outlet is discussed in combination with the previous plunging jet impact assessment. The findings presented may help engineers in designing overfall spillway outlets and improving the energy dissipation performance in high-head dams.

\section{Methods}

Physical model tests were conducted in the hydraulic facility of the State Key Laboratory of Hydraulics and Mountain River Engineering, Sichuan University, China. Using a Froude scale of the physical model, the basic channel design (including the slope, length and width of the channel) was taken to be the prototype overfall spillway on Jinping-I dam. In the model shown in Figure 2, the vertical distance between the weir crest of the overfall spillway and the water surface in the plunge pool was $H=3.26 \mathrm{~m}$. The model facility provided a water head at the weir crest of up to $h=0.23 \mathrm{~m}$ with a water discharge rate of $Q_{\mathrm{w}}=36 \mathrm{l} / \mathrm{s}$. All channel and plunge pool components were made of poly(methyl methacrylate). The bottom angle of the spillway was set to $\alpha=33^{\circ}$. The water discharge was measured with a rectangular thin-wall weir set upstream (accuracy of $\pm 0.1 \mathrm{l} / \mathrm{s}$ ). The pressure on the bottom floor of the plunge pool was measured using piezoresistive pressure sensors (CY201, Test, Inc., China) in combination with an acquisition device 


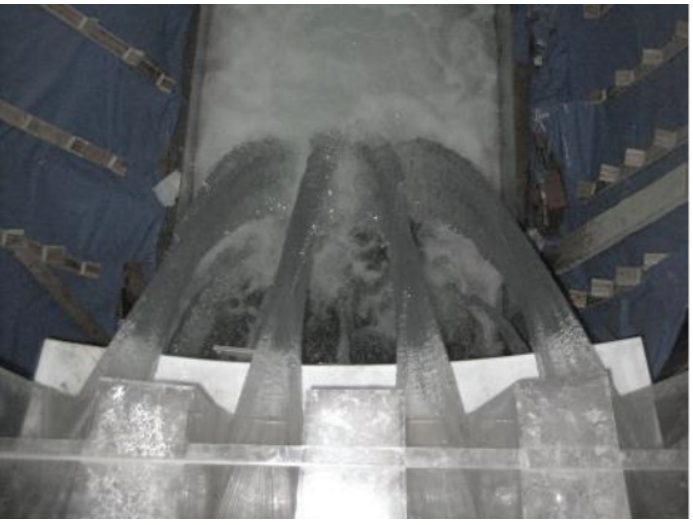

(a)

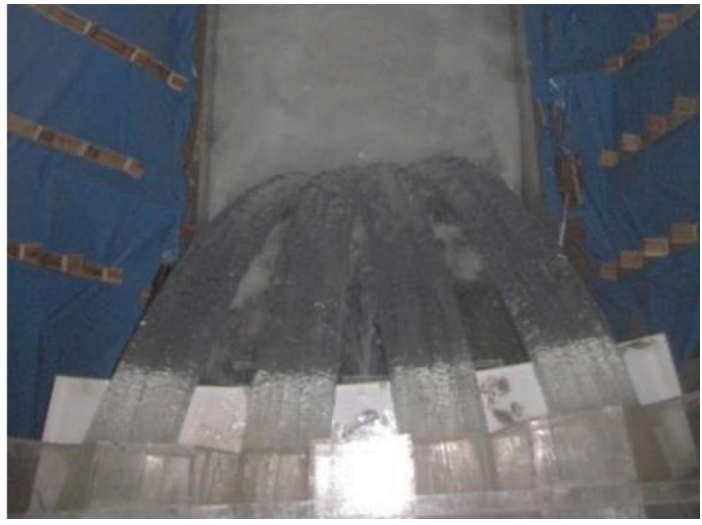

(b)

Figure 2. Jet configurations from overfall spillway (a) with and (b) without a triangular wedge deflector (photos taken by Jun Deng)

(RS485-20, Test, Inc., China). The measurement range was $100 \mathrm{kPa}$ at full scale with an accuracy of $0.1 \%$. All instruments were sampled for $120 \mathrm{~s}$ at $100 \mathrm{~Hz}$, as in previous studies that reported the time-mean impact pressure (Bollaert, 2002; Manso et al., 2008), thus ensuring that sufficient data were available for statistical analysis. To determine the test pressure, the mean dynamic pressure coefficient $C_{\mathrm{p}}$ was calculated using the following expression (Castillo et al., 2014):

1. $C_{\mathrm{p}}=\frac{p_{\mathrm{m}}-Y}{H_{0}}$

where $p_{\mathrm{m}}(\mathrm{m})$ is the maximum time-mean pressure (i.e. the pressure at the stagnation point). In Figure 3, the falling height $H_{0}$ is defined as $H_{0}=H+h$ and $Y$ is the tailwater depth. In the study, a constant tailwater depth of $Y=0.64 \mathrm{~m}$ was considered in all the experiments.

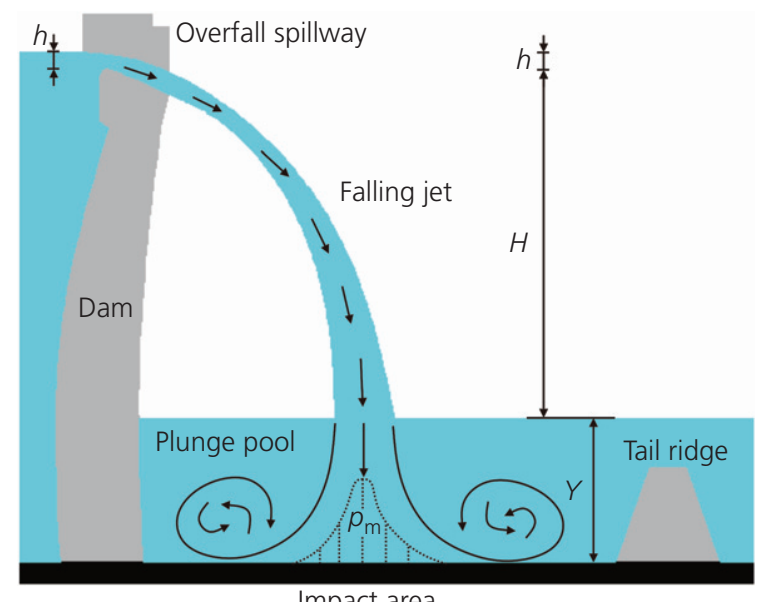

Figure 3. Schematic diagram of plunging jet from an overfall spillway on a dam
Two triangular wedges were set symmetrically on the sidewalls and the general deflection effect on the initial flow pattern was studied as the overfall spillway water flow was released into the air (see Figure 4(a)). According to the plan and side views of the triangular wedge (Figure 4(b)), the inclined face starts from a certain position at the bottom of the sidewall, extending to the end of the spillway; the distance is the triangular wedge length $L_{\mathrm{d}}$. Thus, the final cross-section shows that the width has contracted from the initial channel width $B$ to the outlet width $b$. The thickness of the triangular wedge decreases linearly with the elevation increase, from the bottom width $b_{\mathrm{d}}$ to zero at the height of the triangular wedge $h_{\mathrm{d}}$. In the present study, the initial channel width was set to a constant value of $B=0.157 \mathrm{~m}$. Three different dimensionless parameters were used to assess the design parameter effects on the plunging jet performance: the relative length $L_{\mathrm{d}} / B$, the deflection ratio $b_{\mathrm{d}} / L_{\mathrm{d}}$ and the relative channel width $b / h_{\mathrm{d}}$ (see the Appendix for further details).

According to the specific jet pattern shown in Figure 4(a), it is clear that the transverse-converging water movement through the triangular wedge outlet leads to a non-uniform distribution of the flow discharge rate at the jet cross-section. Thus, a total of 164 testing points were set on the bottom floor and a high density of pressure sensor locations $(0.025 \mathrm{~m}$ intervals $)$ were placed in the main impact area to fully cover the maximum pressure characteristics, as shown in Figure 5. For each given set of design parameters, five water heads were considered ( $h=0.114 \mathrm{~m}, 0.143 \mathrm{~m}, 0.172 \mathrm{~m}, 0.209 \mathrm{~m}$ and $0.229 \mathrm{~m}$ ). The test programmes were carried out for different flow and geometrical parameter conditions, leading to a total of 480 tests. The Froude numbers (Fr) of the approach flow conditions are summarised in Table 1. The flow depths and velocities at the initial cross-section of the triangular wedge, which determine the approach Fr, were calculated using the basic hydraulic theory of developing chute flow (Castro-Orgaz, 2009). Across all test programmes, Fr was in the range 2.32-4.65. Compared 


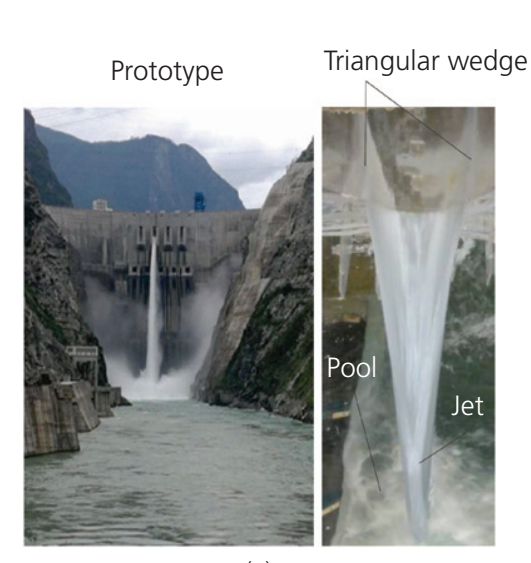

(a)

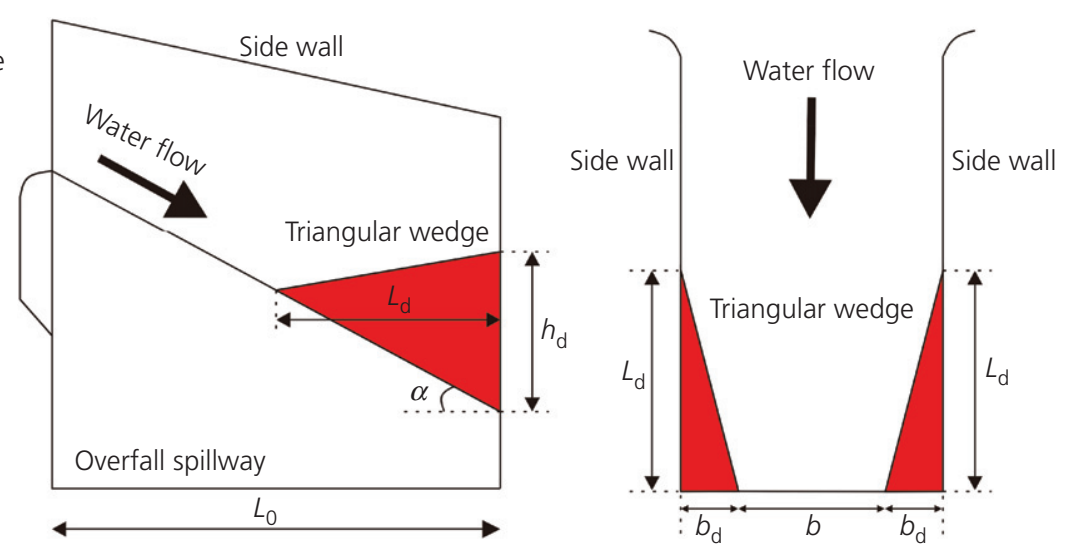

(b)

Figure 4. Plunging jet from overfall spillway: (a) jet pattern in a prototype dam and a model; (b) longitudinal section and plan view of triangular wedge design
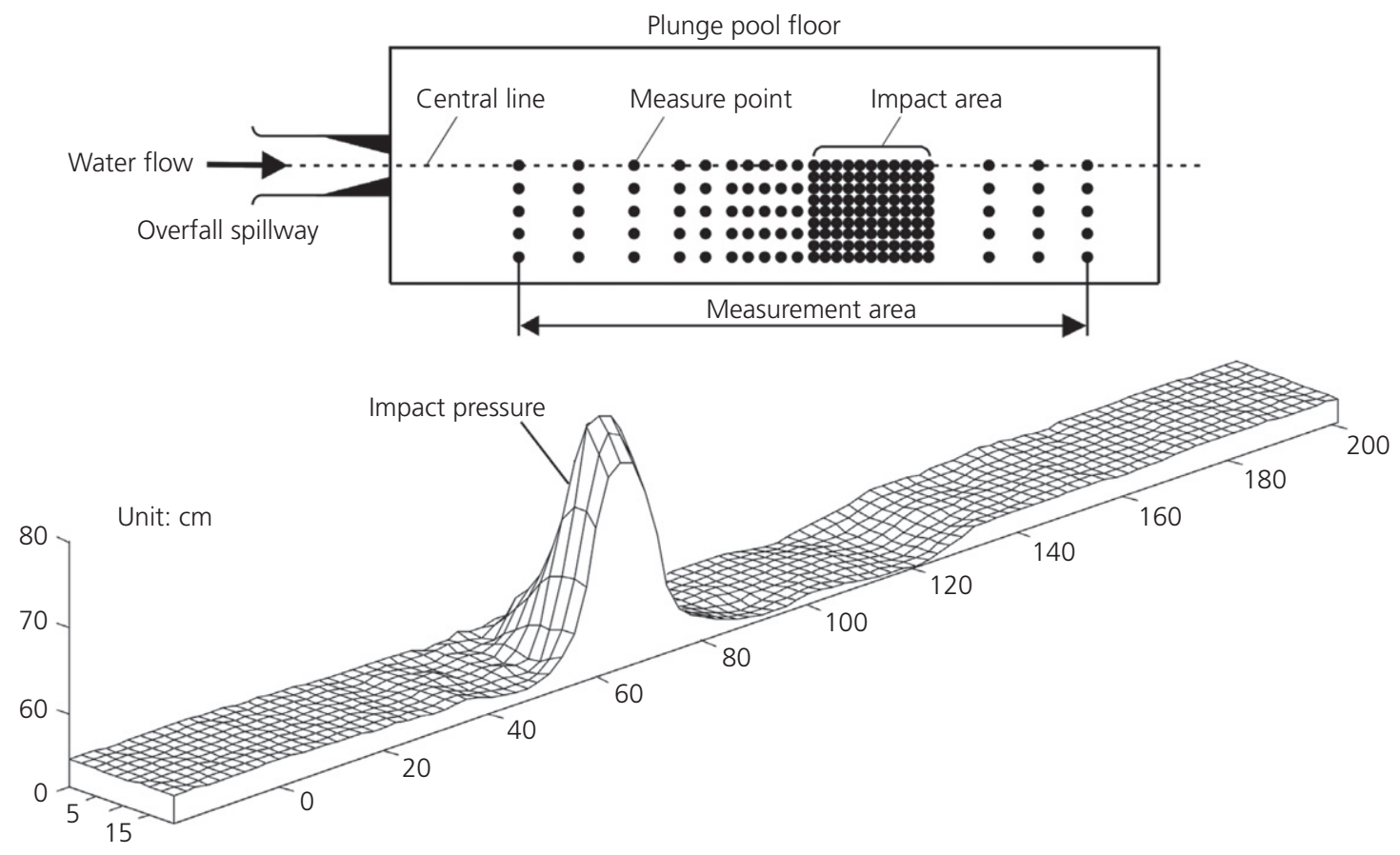

Figure 5. Measurement points in experimental tests

with the previous Fr limitation in ski-jump flow studies (Heller et al., 2005; Juon and Hager, 2000; Wu et al., 2012), the values of $\mathrm{Fr}$ in this work were relatively small, making it more difficult for the jet to diffuse in the longitudinal direction. Numerous studies have confirmed that the water head can be used as an effective independent variable to control the geometrical spreading and impact pressure of a jet from an overfall spillway (Castillo, 2007; Ervine et al., 1997; Puertas and Dolz, 2005), and so the water head is used to determine the approach flow condition in the following sections of this paper.
In terms of the scale effect, it is hard to extrapolate an airwater jet mixture and break-up level in a prototype based on Froude-scaled model results. The scale effect on the air-water properties of supercritical flow cannot be neglected regarding the surface tension and viscosity effects in high-speed air-water flows (Pfister and Chanson, 2014). Dimensional analysis indicates that free jet diffusion depends on the Reynolds number, the Weber number and the turbulent intensity, among other factors (Albertson et al., 1950; Chanson, 2013). The limitations of dynamic similarity and the physical modelling of jets can be 
Table 1. Flow conditions for experimental tests

\begin{tabular}{|c|c|c|c|}
\hline$Q: 1 / s$ & $h: \mathrm{m}$ & $L_{\mathrm{d}}: \mathrm{m}$ & $\mathrm{Fr}$ \\
\hline 12 & 0.114 & 0.086 & 4.65 \\
\hline 12 & 0.114 & 0.114 & 4.45 \\
\hline 12 & 0.114 & 0.150 & 4.20 \\
\hline 12 & 0.114 & 0.157 & 4.15 \\
\hline 12 & 0.114 & 0.214 & 3.74 \\
\hline 12 & 0.114 & 0.286 & 3.20 \\
\hline 12 & 0.114 & 0.357 & 2.63 \\
\hline 17 & 0.143 & 0.086 & 4.16 \\
\hline 17 & 0.143 & 0.114 & 4.00 \\
\hline 17 & 0.143 & 0.150 & 3.79 \\
\hline 17 & 0.143 & 0.157 & 3.75 \\
\hline 17 & 0.143 & 0.214 & 3.41 \\
\hline 17 & 0.143 & 0.286 & 2.97 \\
\hline 17 & 0.143 & 0.357 & 2.51 \\
\hline 23 & 0.172 & 0.086 & 3.80 \\
\hline 23 & 0.172 & 0.114 & 3.66 \\
\hline 23 & 0.172 & 0.150 & 3.49 \\
\hline 23 & 0.172 & 0.157 & 3.45 \\
\hline 23 & 0.172 & 0.214 & 3.17 \\
\hline 23 & 0.172 & 0.286 & 2.80 \\
\hline 23 & 0.172 & 0.357 & 2.41 \\
\hline 31 & 0.209 & 0.086 & 3.51 \\
\hline 31 & 0.209 & 0.114 & 3.39 \\
\hline 31 & 0.209 & 0.150 & 3.25 \\
\hline 31 & 0.209 & 0.157 & 3.22 \\
\hline 31 & 0.209 & 0.214 & 2.98 \\
\hline 31 & 0.209 & 0.286 & 2.67 \\
\hline 31 & 0.209 & 0.357 & 2.35 \\
\hline 36 & 0.229 & 0.086 & 3.39 \\
\hline 36 & 0.229 & 0.114 & 3.28 \\
\hline 36 & 0.229 & 0.150 & 3.15 \\
\hline 36 & 0.229 & 0.157 & 3.12 \\
\hline 36 & 0.229 & 0.214 & 2.90 \\
\hline 36 & 0.229 & 0.286 & 2.62 \\
\hline 36 & 0.229 & 0.357 & 2.32 \\
\hline
\end{tabular}

identified from previous investigations on the reduction of scale effects (Chanson, 2009; Heller, 2011). The Weber number $\left(\mathrm{We}=\rho V_{0}^{2} B / \sigma\right)$ should exceed $10^{3}$ and the Reynolds number $\left(\operatorname{Re}=V_{0} B / v\right)$ should exceed $10^{5}(\rho$ is the water density, $\sigma$ is the surface tension between the air and water, $V_{0}$ can be estimated as $V_{0}=\left(2 \boldsymbol{g} H_{0}\right)^{0.5}$ and $v$ is the kinematic water viscosity. In the present study, minimum values of $\mathrm{We}=1.8 \times 10^{4}$ and $\operatorname{Re}=4.6 \times 10^{5}$ were set. Due to the high drop height of a falling jet from an overfall spillway, as shown in Figure 4(a), the clear contraction in the transverse direction causes the water jet to form a thin nappe. This is mainly because the water close to the sidewall is deflected by the triangular wedge (as shown in the model). The focus of the present study was on how the mean dynamic pressure in the plunge pool can be reduced by varying the design parameters of the triangular wedge.

\section{Results and discussion}

\subsection{Comparison of rectangular and triangular wedge jet impacts}

According to the basic formula established by Castillo et al. (2015), the thickness of a rectangular jet from an overfall spillway at the entrance to a plunge pool is

$$
\text { 2. } B_{\mathrm{j}}=\frac{q}{\sqrt{2 \boldsymbol{g} H}}+4 \phi \sqrt{h}(\sqrt{2 H}-2 \sqrt{h})
$$

where $q$ is the flow discharge per unit width. The coefficient $\phi$ is determined by basic flow conditions as

3. $\phi=1.07\left(\frac{q^{0.43} K^{1.22} C_{\mathrm{d}}^{0.19}}{14.95 \boldsymbol{g}^{0.50}}\right)$

where $\boldsymbol{g}$ is gravitational acceleration. The constant 1.07 is an experimental parameter for estimating the turbulence characteristic in the break-up development of a rectangular falling jet (Castillo, 2006; Ervine and Falvey, 1987). Castillo (2006) suggested that $K=0.85$ and $C_{\mathrm{d}}=2.10$, and the jet break-up length for the overfall spillway nappe flow would follow as

4. $\quad L_{\mathrm{b}}=\frac{K B_{\mathrm{j}} \mathrm{Fr}_{\mathrm{j}}^{2}}{C^{0.82}}$

where $\mathrm{Fr}_{\mathrm{j}}$ is the Froude number at the entrance and $C$ is a turbulence parameter determined by $\mathrm{Fr}_{\mathrm{j}}$ and the turbulence intensity at the entrance. In the present conditions, without a triangular wedge, the theoretical $H_{0} / h=6.13-9.96$, which indicates a fully developed jet for all model tests. The minimum $Y / B_{\mathrm{j}}$ is 9.4 , which is greater than the value of 5.5 suggested as the limiting effective water cushion depth (Castillo et al., 2015).

In terms of the mean dynamic pressure coefficient $\left(C_{\mathrm{p}}\right)$ without a triangular wedge, theoretical values can be estimated for all water head conditions according to previous investigations on the mean impact pressure of rectangular plunging jets (Castillo et al., 2014; Ervine et al., 1997; Puertas, 1994), as shown in Figure 6. Firstly, the maximum $C_{\mathrm{p}}$ for each value of $h$ gives the traditional estimation result. The value of $C_{\mathrm{p}}$ is affected by the design of the triangular wedge. For a high water head $(h=0.229 \mathrm{~m}), C_{\mathrm{p}}$ can decrease to about $10 \%$ of its maximum value. Secondly, the tested values of $C_{\mathrm{p}}$ are greater for small values of $b_{\mathrm{d}} / L_{\mathrm{d}}$ than for large values of $b_{\mathrm{d}} / L_{\mathrm{d}}$. This trend confirms that a simple triangular wedge design at the overfall spillway outlet effectively deflects the jet flow, resulting in diffusion in the longitudinal direction. This prevents overconcentration of the plunging jet at the entrance to the plunge pool and progressively reduces the jet impact. On the basis of a low discharge per unit width and a high jet break-up at the entrance to the plunge pool, the reference lines for $H_{0} / L_{\mathrm{b}}=1.0$ and $H_{0} / L_{\mathrm{b}} \geq 1.6$ indicate that a well-designed triangular wedge can improve the surface spread of a jet released from an overfall spillway and reduce the mean dynamic pressure. The data shown in Figure 6 are highly scattered because the jet pattern is affected by the deflection, making it difficult to give a reliable assessment of variations in the jet pattern. Moreover, 


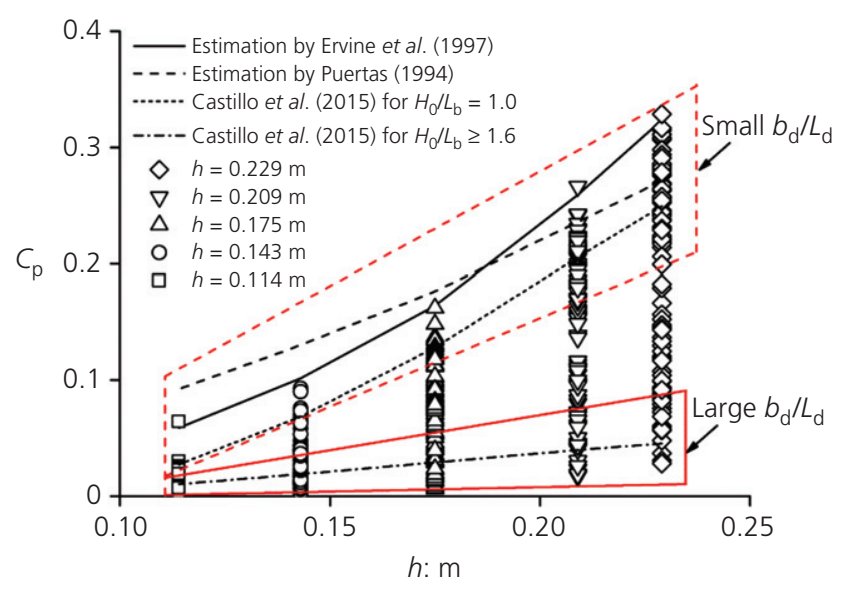

Figure 6. Comparison of $C_{p}$ with a triangular wedge against previous estimations of regular jet impact

the effect of different scaled models on surface tension and jet aeration development should be taken into consideration.

\subsection{Triangular wedge jet pattern}

The effect of Fr on the jet impact pressure for various triangular wedge design parameters is shown in Figure 7. For $\mathrm{Fr}<3.3$, the scattered data indicate that the effects of geometrical parameters such as $L_{\mathrm{d}} / B$ and $b / h_{\mathrm{d}}$ in the case of a high water head are significant and should be considered further. As Fr increases above 3.6-3.9, the value of $C_{\mathrm{p}}$ generally decreases. A value of zero indicates full energy dissipation in the plunge pool for the present tailwater condition. This is mainly because the deflection effect of a triangular wedge on the jet results in a ski-jump flow feature, and large values of Fr improve jet diffusion in air. As the flow Froude number combined with a triangular wedge modifies water diffusion in the air, the jet spread can be used as a baseline for analysing the

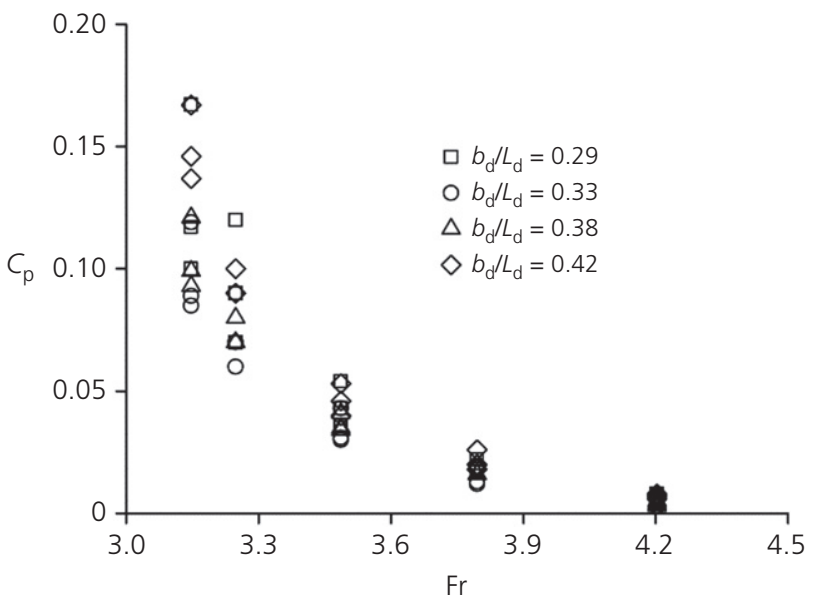

Figure 7. Effect of flow Froude number on $C_{p}\left(L_{d}=0.150 \mathrm{~m}\right)$ pressure reduction of overfall spillway jet flows in the presence of a triangular wedge.

Figure 8 shows the main flow features in the presence of a symmetrical triangular wedge sidewall. Due to the abrupt deflection at the end of the overfall spillway, there is a lateral contraction of water flow in the channel. The jet expands vertically in the downstream direction as it drops into the air. This laterally thin and longitudinally diffuse nappe is different from the standard configuration that occurs in a rectangular overfall spillway outlet (Castillo, 2006). The lateral contraction begins at the upstream end of the triangular wedge. Because of the inclined wall of the triangular wedge, the lateral contraction develops gradually until the downstream end of the wedge. The plane triangle shape close to the outlet represents the developing lateral contraction of the falling jet. Both outer axes of the jet converge, and the jet remains thin in the transverse direction but expands in the normal direction.

Compared with previous lateral-contraction designs of spillway outlets, such as slit-type designs (Wu et al., 2015) and flared piers (Li et al., 2012), the triangular wedge deflects the water flow differently at the elevation direction. In the vertical direction, the water flow contraction gradually weakens from the bottom to the top of the triangular wedge whereas, in the transverse direction, the water in the middle of the overfall spillway remains supercritical. These effects combine to decrease the kinetic energy of the water near the sidewall while gradually increasing the lateral velocity. This ensures lateral contraction generated in the channel, which further develops in the air, leading to a thin and vertical jet through the rapid enhancement of the kinetic energy of water jet. Consequently, the triangular wedge design prevents the choking phenomenon of water flow in the channel and guarantees effective jet deflection from the dam toe. This is beneficial for flow discharge operations and overfall spillway structure safety as it
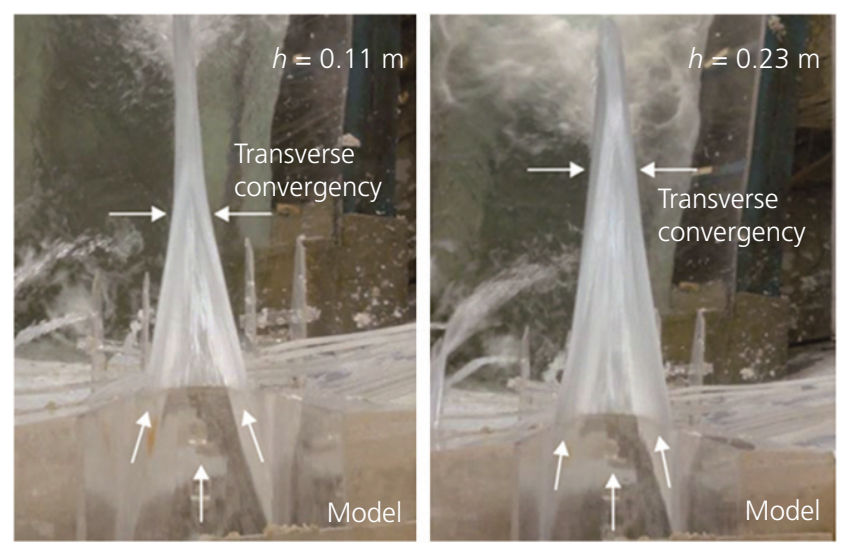

Figure 8. Lateral-contraction development of jet pattern in the presence of a triangular wedge 
avoids scouring close to the dam foundations (Farinha et al., 2015).

\subsection{Effect of design parameters}

Figure 9(a) shows that the effect of the triangular wedge length on $C_{\mathrm{p}}$. With an increase in $L_{\mathrm{d}} / B$, ranging from 0.80 to 1.80 , the value of $C_{\mathrm{p}}$ increases gradually, indicating that a moderately short triangular wedge is necessary to reduce the jet plunging impact. Once $L_{\mathrm{d}} / B$ exceeds about 1.80 , the trend of increasing $C_{\mathrm{p}}$ with $L_{\mathrm{d}} / B$ is not obvious. For $h_{\mathrm{d}} / h$ in the range $0.81-1.51$, there is no obvious effect of $h_{\mathrm{d}} / h$ on $C_{\mathrm{p}}$. As the overfall spillway on a high dam is usually short with a relatively large bottom slope (Castillo et al., 2015), this indicates that, once the height of the triangular wedge approaches the water head for $h_{\mathrm{d}} / h>0.8$, the effect of contraction due to deflection on the jet pattern becomes independent of $h_{\mathrm{d}} / h$. Figure 9 (b) shows that, for $L_{\mathrm{d}} / B>0.95$, an increase in $b_{\mathrm{d}} / L_{\mathrm{d}}$ first causes $C_{\mathrm{p}}$ to decrease gradually and subsequently increase. For $L_{\mathrm{d}} / B=0.55$, the short length of the triangular wedge results in a continuous reduction of $C_{\mathrm{p}}$ as $b_{\mathrm{d}} / L_{\mathrm{d}}$ increases from 0.2 to 0.6 . For a given triangular wedge length and water head conditions, there is a critical triangular wedge thickness at which the minimum mean dynamic pressure occurs. As $b_{\mathrm{d}} / L_{\mathrm{d}}$ is less than this critical condition, the decrease in $C_{\mathrm{p}}$ for different values of $L_{\mathrm{d}} / B$ displays almost the same trend. As shown in Figure 9(c), with an increase $b / h_{\mathrm{d}}, C_{\mathrm{p}}$ initially decreases to a certain value and subsequently increases, as the contractiondeflection effect is developing. Above a certain value of $b / h_{\mathrm{d}}$, $C_{\mathrm{p}}$ increases.

The main reason for these phenomena is the contractiondeflection effect of the triangular wedge parameters on the releasing jet pattern. As the water flows through the triangular wedge structure, the inclined wall forces the water to contract in the lateral direction, generating a long and narrow diffusion jet plunging into the pool. For a constant water discharge, the uniform flow rate at the jet cross-section results in a relatively low mean dynamic pressure because the

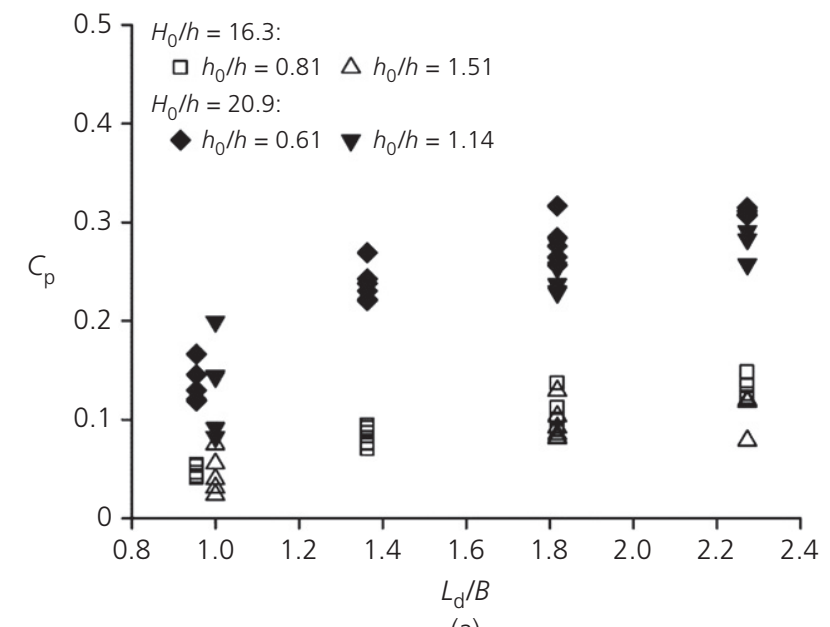

(a)

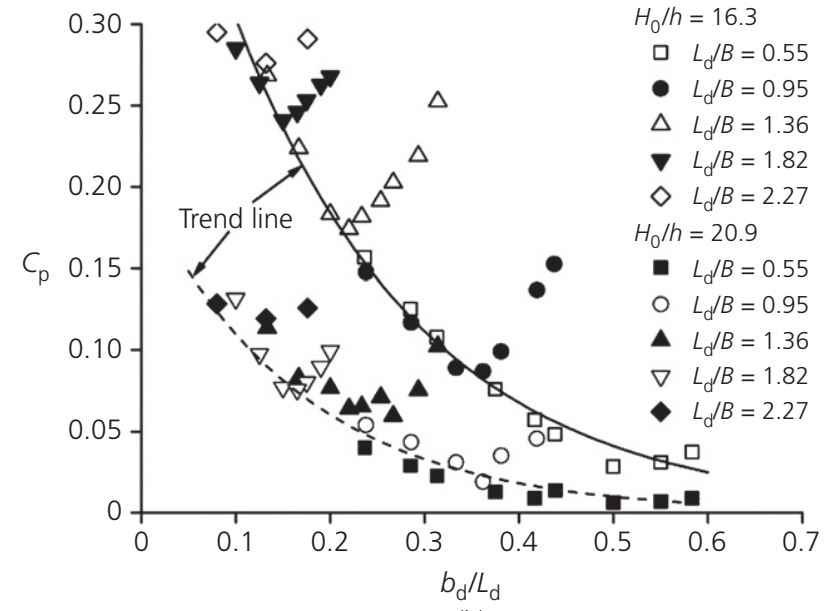

(b)

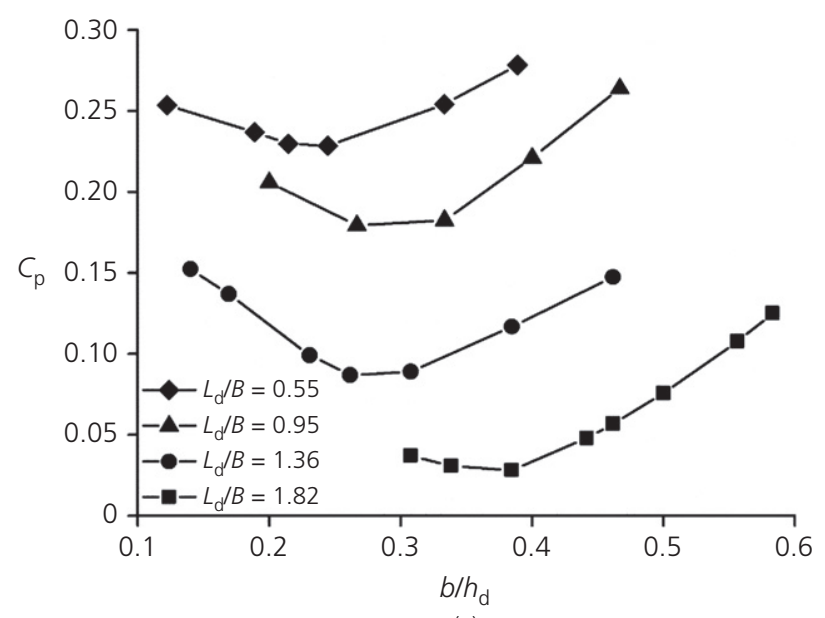

(c)

Figure 9. Effects of design parameters on $C_{p}$ : (a) $L_{d} / B$; (b) $b / L_{d}$; (c) $b / h_{d}$ for $H_{0} / h=15.3$ 
discharge per unit width of the plunging jet reduces. Good performance of contraction-deflection is indicated by coupling of the deflection ratio $b_{\mathrm{d}} / L_{\mathrm{d}}$ with the relative channel width $b / h_{\mathrm{d}}$. A lower $b_{\mathrm{d}} / L_{\mathrm{d}}$ with a larger $b / h_{\mathrm{d}}$ may drive more water to be released from lower elevations at the end of the crosssection of the spillway. This leads to more water dropping close to upstream in the pool. In contrast, a higher $b_{\mathrm{d}} / L_{\mathrm{d}}$ with a smaller $b / h_{\mathrm{d}}$ may cause the water flow to be concentrated further downstream. Thus, an optimised triangular wedge design should enable uniform diffusion of the jet in the air and reduce the plunging impact effect on the downstream region of the pool.

The variation in $C_{\mathrm{p}}$ is also a result of the jet break-up level, which is affected by the triangular wedge deflection. As shown in Figure 10, a lower water head and a higher falling height produce a more pronounced decrease in $C_{\mathrm{p}}$. This reduction is illustrated in terms of low jet break-up $\left(H_{0} / L_{\mathrm{b}}=1.0\right)$ and high break-up $\left(H_{0} / L_{\mathrm{b}} \geq 1.6\right)$ conditions, where $L_{\mathrm{b}}$ is the jet break-up length (Ervine et al., 1997). As circular jets with a higher radial degree of turbulent diffusion undergo enhanced lateral spreading and aeration compared with rectangular jets (Beltaos and Rajaratnam, 1973, 1976; Bollaert, 2002; Franzetti and Tanda, 1987; Hartung and Häusler, 1973), it can be deduced that the vertical spreading of a jet driven by a triangular wedge will enhance turbulent diffusion and the break-up level. For small lateral-contraction deflections $\left(b_{\mathrm{d}} / L_{\mathrm{d}}<0.10-0.20\right)$, the rate of decrease in the gradient of $C_{\mathrm{p}}$ with respect to $H_{0} / h$ is greater than that for moderate lateral-contraction deflections $\left(0.20<b_{\mathrm{d}} / L_{\mathrm{d}}\right.$ $<0.50)$. This indicates that, once the lateral contraction with small $b_{\mathrm{d}} / L_{\mathrm{d}}$ is not sufficient, deflection of the triangular wedge may strengthen the jet core and weaken the lateral diffusion of turbulence, resulting in a high impact on the plunge pool.

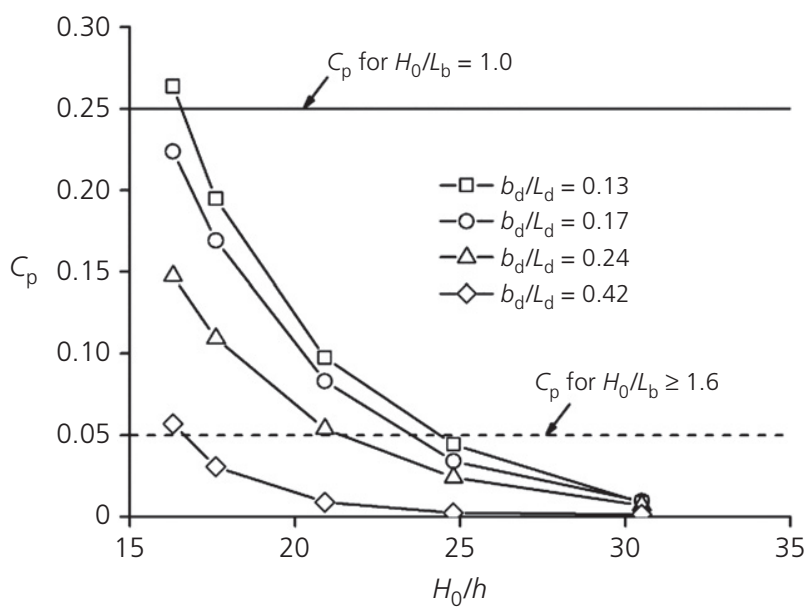

(a)

\subsection{Mean dynamic pressure coefficient $\left(C_{p}\right)$}

The effects of different design parameters on $C_{\mathrm{p}}$ under different water head conditions are shown in Figure 11(a), following the empirical expression

5. $C_{\mathrm{p}}=\frac{k}{b / h_{\mathrm{d}}} \exp \left(-6.50 \frac{b_{\mathrm{d}}}{L_{\mathrm{d}}}\right)$

where

6.

$$
\begin{aligned}
k= & 3.84 \exp \left(-0.18 \frac{H_{0}}{h}\right) \text { for } 15.3 \leq \frac{H_{0}}{h} \leq 29.5 \text { and } \\
& 2.32 \leq \mathrm{Fr} \leq 4.65
\end{aligned}
$$

The exponential trends in $C_{\mathrm{p}}$ are in good agreement with previous mean dynamic pressure measurements for regular falling jets. A general relationship is (Castillo et al., 2015)

7. $C_{\mathrm{p}}=m \exp \left(-n \frac{Y}{B_{\mathrm{j}}}\right)$

where $B_{\mathrm{j}}$ is the impingement jet thickness at the water cushion surface. The coefficients $m$ and $n$ are determined by the plunging jet break-up level $H_{0} / L_{\mathrm{b}}$.

As $H_{0} / h$ increases, the coefficient $k$ decreases, resulting in a smaller value of $C_{\mathrm{p}}$. Thus, as well as the effect of a low water head $h$, a large value of $H_{0}$ may affect the jet break-up. According to various test data (Albertson et al., 1950; Bollaert and Schleiss, 2003a; Ervine et al., 1997; Franzetti and Tanda, 1987), the relationship between $H_{0} / L_{\mathrm{b}}$ and the coefficients $m$ and $n$ is shown in Figure 11(b). The jet break-up

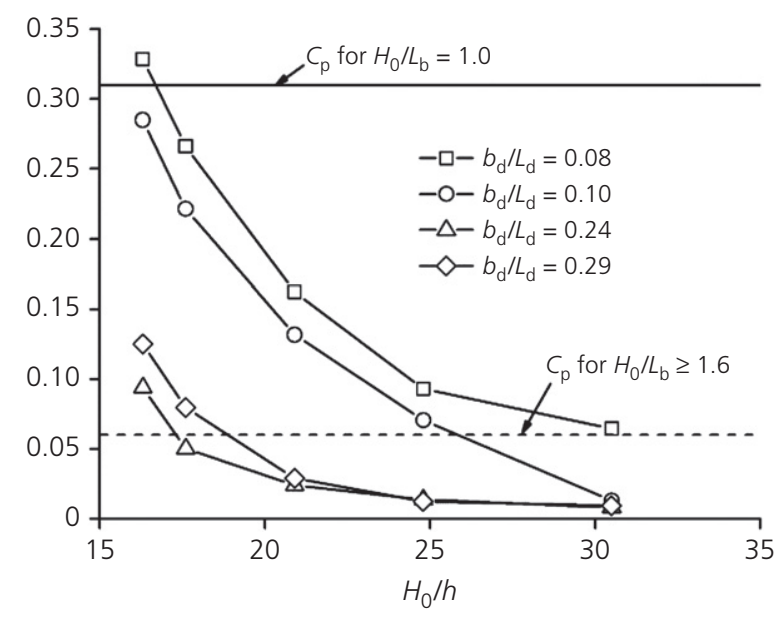

(b)

Figure 10. Effect of water head on $C_{p}$ : (a) $b=0.086 \mathrm{~m}, Y / b=7.9$; (b) $b=0.100 \mathrm{~m}, Y / b=6.8$ 


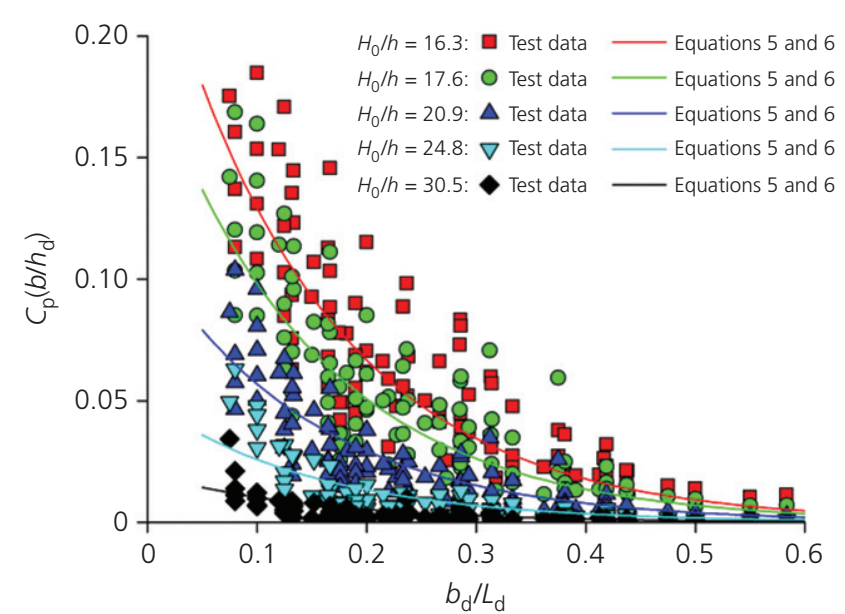

(a)

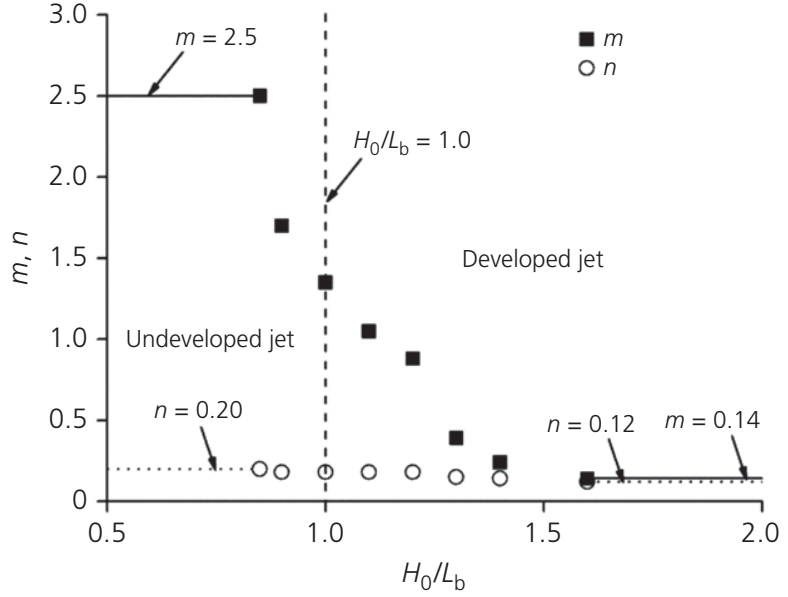

(b)

Figure 11. (a) $C_{p}$ as a function of water head and design parameters; (b) Relationship between $H_{0} / L_{b}$ and coefficients $m$ and $n$

level reflects the jet aeration effect on the plunging impact. An increase in $H_{0}$ or a decrease in $L_{\mathrm{b}}$ can improve the jet aeration level at the impingement point, and an increase in jet aeration leads to a reduction in the mean dynamic pressure (Manso et al., 2004; Xu et al., 2004). An increase in $H_{0} / L_{\mathrm{b}}$ results in a significant decrease in $m$. A slight decrease in $n$ can cause $C_{\mathrm{p}}$ to increase, but high values of the ratio $\mathrm{m} / \mathrm{n}$ confirm that $m$ is the primary factor. Thus, a large $H_{0} / L_{\mathrm{b}}$ leads to a reduction in $C_{\mathrm{p}}$.

Besides the mean pressure, pressure fluctuation is another parameter that is important in assessing bottom slab stability and the structural safety of a plunge pool. The pressure fluctuation of a plunging jet is strongly affected by the jet turbulence intensity and the break-up level at the entrance to the plunge pool. Firstly, there is a positive correlation between the water head and pressure fluctuation (Bollaert and Schleiss, 2003b, 2005), with the root mean square (RMS) value of the pressure fluctuation decreasing as the water head decreases (the water head determines the mean pressure on the plunge pool). Secondly, for a developed jet impact $(Y / b>5)$, a decrease in the RMS value as $Y / b$ increases indicates that improving the flow surface spread by decreasing the flow thickness at the entrance to the plunge pool is an effective way of reducing the dynamic pressure fluctuation. The limitations of the present study mean that, for similar water head conditions, the relationship between the deflected jet configuration and pressure fluctuation should be examined in future research.

Based on the present study, it is feasible that an appropriate deflector on an overfall spillway can achieve adequate jet diffusion and impact pressure reduction, especially for relatively low Froude number conditions. Different from previous hydraulic control techniques to ensure energy dissipation and structural safety, a triangular wedge design at the end of an overfall spillway provides an effective means of improving the spread of the impingement jet and reducing the threat of impact damage. Based on the geometric shape of the outlet, it should be easy to assess the jet impact. Combined with other outlet design forms, such as circular-shape, lateral-contraction and leak-floor deflectors, this extends the ski-jump energy dissipation application for complicated engineering geology and flood discharge operation conditions. The present findings represent an important addition to the literature on falling jet impacts and will assist engineers in designing overfall spillways for high-head hydraulic engineering.

\section{Conclusions}

Optimal design of a triangular wedge at the end of an overfall spillway in a high-head dam was examined. The effects of different design parameters were analysed in detail based on laboratory data on the mean pressure coefficient. The triangular wedge design is an effective method that causes the water flow to contract and deflect in the lateral direction. For a certain length of triangular wedge, the optimal deflection ratio in combination with a moderate contraction ratio results in a low jet impact on the plunge pool. An empirical relationship for estimating the mean pressure coefficient was developed based on the design parameters and water head conditions; this confirms that a triangular wedge structure improves the lateral spreading and break-up level of a plunging jet. This offers a practical geometric design for a high-head overfall spillway, reducing the threat of jet energy dissipation damage.

The present study was carried out under laboratory conditions. To extrapolate the results to prototype operations, designers should consider differences in jet patterns (e.g. the jet break-up level and air-water jet diffusion in the plunge pool) that are 
strongly affected by the scale effect. To improve the reliability and rationality of triangular wedge designs, further observations and measurements are required on differently scaled models and prototypes, especially those concerning strong jet aeration and turbulent interactions.

\section{Acknowledgements}

The authors are grateful for the financial support from the National Natural Science Foundation of China (grants 51979183 and 51939007) and the Sichuan Science and Technology Program (grant 2019JDTD0007).

\section{Appendix: Experimental parameters of the test programme}

\begin{tabular}{|c|c|c|c|c|c|c|c|c|c|c|c|c|c|c|}
\hline Test & $L_{\mathrm{d}}: \mathrm{m}$ & $h_{\mathrm{d}}: \mathrm{m}$ & $b_{d}: m$ & $b: m$ & Test & $L_{\mathrm{d}}: m$ & $h_{\mathrm{d}}: \mathrm{m}$ & $b_{\mathrm{d}}: m$ & $b: m$ & Test & $L_{\mathrm{d}}: \mathrm{m}$ & $h_{\mathrm{d}}: m$ & $b_{\mathrm{d}}: m$ & $b: m$ \\
\hline 1 & 0.086 & 0.186 & 0.020 & 0.117 & 33 & 0.150 & 0.143 & 0.063 & 0.031 & 65 & 0.286 & 0.257 & 0.036 & 0.086 \\
\hline 2 & 0.086 & 0.186 & 0.024 & 0.108 & 34 & 0.150 & 0.186 & 0.066 & 0.026 & 66 & 0.286 & 0.214 & 0.036 & 0.086 \\
\hline 3 & 0.086 & 0.186 & 0.027 & 0.103 & 35 & 0.157 & 0.257 & 0.029 & 0.100 & 67 & 0.286 & 0.143 & 0.036 & 0.086 \\
\hline 4 & 0.086 & 0.186 & 0.032 & 0.093 & 36 & 0.157 & 0.257 & 0.036 & 0.086 & 68 & 0.286 & 0.186 & 0.036 & 0.086 \\
\hline 5 & 0.086 & 0.186 & 0.036 & 0.086 & 37 & 0.157 & 0.257 & 0.043 & 0.071 & 69 & 0.286 & 0.186 & 0.043 & 0.071 \\
\hline 6 & 0.086 & 0.186 & 0.038 & 0.082 & 38 & 0.157 & 0.257 & 0.050 & 0.057 & 70 & 0.286 & 0.257 & 0.047 & 0.063 \\
\hline 7 & 0.086 & 0.186 & 0.043 & 0.071 & 39 & 0.157 & 0.257 & 0.061 & 0.034 & 71 & 0.286 & 0.214 & 0.047 & 0.063 \\
\hline 8 & 0.086 & 0.186 & 0.047 & 0.063 & 40 & 0.214 & 0.186 & 0.029 & 0.100 & 72 & 0.286 & 0.143 & 0.047 & 0.063 \\
\hline 9 & 0.086 & 0.186 & 0.050 & 0.057 & 41 & 0.214 & 0.214 & 0.029 & 0.100 & 73 & 0.286 & 0.186 & 0.047 & 0.063 \\
\hline 10 & 0.114 & 0.186 & 0.027 & 0.103 & 42 & 0.214 & 0.186 & 0.036 & 0.086 & 74 & 0.286 & 0.186 & 0.050 & 0.057 \\
\hline 11 & 0.114 & 0.186 & 0.033 & 0.092 & 43 & 0.214 & 0.214 & 0.036 & 0.086 & 75 & 0.286 & 0.257 & 0.051 & 0.055 \\
\hline 12 & 0.114 & 0.186 & 0.036 & 0.086 & 44 & 0.214 & 0.143 & 0.036 & 0.086 & 76 & 0.286 & 0.257 & 0.054 & 0.049 \\
\hline 13 & 0.114 & 0.186 & 0.043 & 0.071 & 45 & 0.214 & 0.214 & 0.043 & 0.071 & 77 & 0.286 & 0.214 & 0.054 & 0.049 \\
\hline 14 & 0.114 & 0.186 & 0.047 & 0.063 & 46 & 0.214 & 0.143 & 0.043 & 0.071 & 78 & 0.286 & 0.143 & 0.054 & 0.049 \\
\hline 15 & 0.114 & 0.186 & 0.050 & 0.057 & 47 & 0.214 & 0.186 & 0.043 & 0.071 & 79 & 0.286 & 0.186 & 0.054 & 0.049 \\
\hline 16 & 0.114 & 0.186 & 0.054 & 0.049 & 48 & 0.214 & 0.186 & 0.047 & 0.063 & 80 & 0.286 & 0.186 & 0.057 & 0.043 \\
\hline 17 & 0.114 & 0.186 & 0.057 & 0.043 & 49 & 0.214 & 0.214 & 0.050 & 0.057 & 81 & 0.286 & 0.143 & 0.061 & 0.034 \\
\hline 18 & 0.114 & 0.186 & 0.063 & 0.031 & 50 & 0.214 & 0.143 & 0.050 & 0.057 & 82 & 0.286 & 0.257 & 0.063 & 0.031 \\
\hline 19 & 0.150 & 0.186 & 0.036 & 0.086 & 51 & 0.214 & 0.186 & 0.050 & 0.057 & 83 & 0.357 & 0.257 & 0.029 & 0.100 \\
\hline 20 & 0.150 & 0.186 & 0.043 & 0.071 & 52 & 0.214 & 0.186 & 0.054 & 0.049 & 84 & 0.357 & 0.214 & 0.029 & 0.100 \\
\hline 21 & 0.150 & 0.214 & 0.043 & 0.071 & 53 & 0.214 & 0.214 & 0.057 & 0.043 & 85 & 0.357 & 0.186 & 0.029 & 0.100 \\
\hline 22 & 0.150 & 0.143 & 0.043 & 0.071 & 54 & 0.214 & 0.143 & 0.057 & 0.043 & 86 & 0.357 & 0.143 & 0.029 & 0.100 \\
\hline 23 & 0.150 & 0.143 & 0.047 & 0.063 & 55 & 0.214 & 0.186 & 0.057 & 0.043 & 87 & 0.357 & 0.143 & 0.036 & 0.086 \\
\hline 24 & 0.150 & 0.186 & 0.050 & 0.057 & 56 & 0.214 & 0.143 & 0.061 & 0.043 & 88 & 0.357 & 0.143 & 0.043 & 0.071 \\
\hline 25 & 0.150 & 0.214 & 0.050 & 0.057 & 57 & 0.214 & 0.186 & 0.063 & 0.031 & 89 & 0.357 & 0.257 & 0.047 & 0.063 \\
\hline 26 & 0.150 & 0.143 & 0.050 & 0.057 & 58 & 0.214 & 0.143 & 0.063 & 0.031 & 90 & 0.357 & 0.214 & 0.047 & 0.063 \\
\hline 27 & 0.150 & 0.186 & 0.054 & 0.049 & 59 & 0.214 & 0.186 & 0.067 & 0.023 & 91 & 0.357 & 0.186 & 0.047 & 0.063 \\
\hline 28 & 0.150 & 0.186 & 0.057 & 0.043 & 60 & 0.286 & 0.214 & 0.021 & 0.114 & 92 & 0.357 & 0.143 & 0.047 & 0.063 \\
\hline 29 & 0.150 & 0.214 & 0.057 & 0.043 & 61 & 0.286 & 0.257 & 0.029 & 0.100 & 93 & 0.357 & 0.143 & 0.054 & 0.049 \\
\hline 30 & 0.150 & 0.143 & 0.057 & 0.043 & 62 & 0.286 & 0.214 & 0.029 & 0.100 & 94 & 0.357 & 0.257 & 0.063 & 0.031 \\
\hline 31 & 0.150 & 0.186 & 0.063 & 0.031 & 63 & 0.286 & 0.143 & 0.029 & 0.100 & 95 & 0.357 & 0.214 & 0.063 & 0.031 \\
\hline 32 & 0.150 & 0.214 & 0.063 & 0.031 & 64 & 0.286 & 0.186 & 0.029 & 0.100 & 96 & 0.357 & 0.186 & 0.063 & 0.031 \\
\hline
\end{tabular}

REFERENCES

Albertson ML, Dai Y, Jensen R and Rouse H (1950) Diffusion of submerged jets. Transactions of the American Society of Civil Engineers 115(1): 639-664.

Beltaos S (1976) Oblique impingement of plane turbulent jets. Journal of the Hydraulics Division 102(9): 1177-1192.

Beltaos S and Rajaratnam N (1973) Plane turbulent impinging jets. Journal of Hydraulic Research 11(1): 29-59.

Beltaos S and Rajaratnam N (1976) Impinging circular turbulent jets. Journal of the Hydraulics Division 100(10): 1313-1328.

Bollaert EFR (2002) Transient Water Pressures in Joints and Formation of Rock Scour due to High-Velocity Jet Impact. Laboratoire de Constructions Hydrauliques, Ecole Polytechnique Fédérale de Lausanne, Lausanne, Switzerland.

Bollaert E and Schleiss AJ (2003a) Scour of rock due to the impact of plunging high velocity jets. Part I: A state-of-the-art review. Journal of Hydraulic Research 41(5): 451-464.
Bollaert E and Schleiss AJ (2003b) Scour of rock due to the impact of plunging high velocity jets. Part II: Experimental results of dynamic pressures at pool bottoms and in one- and twodimensional closed end rock joints. Journal of Hydraulic Research 41(5): 465-480.

Bollaert E and Schleiss AJ (2005) Physically based model for evaluation of rock scour due to high velocity jet impact. Journal of Hydraulic Engineering 131(4): 153-165.

Castillo L (2006) Aerated jets and pressure fluctuation in plunge pools. In Proceedings of the 7th International Conference on Hydroscience and Engineering. Drexel University, Philadelphia, PA, USA, pp. $1-23$.

Castillo L (2007) Pressure characterization of undeveloped and developed jets in shallow and deep pool. Proceedings of the 32th IAHR Congress, Venice, Italy. Corila, Venice, Italy, pp. 645-655.

Castillo L, Carrillo JM and Sordo-Ward Á (2014) Simulation of overflow nappe impingement jets. Journal of Hydroinformatics 16(4): 922-940. 
Castillo L, Carrillo J and Blázquez A (2015) Plunge pool dynamic pressures: a temporal analysis in the nappe flow case. Journal of Hydraulic Research 53(1): 101-118.

Castro-Orgaz O (2009) Hydraulics of developing chute flow. Journal of Hydraulic Research 47(2): 185-194.

Chanson H (2009) Turbulent air-water flows in hydraulic structures: dynamic similarity and scale effects. Environmental Fluid Mechanics 9(2): 125-142.

Chanson H (2013) Hydraulics of aerated flows: qui pro quo? Journal of Hydraulic Research 51(3): 223-243.

Cola R (1965) Energy dissipation of a high-velocity vertical jet entering a basin. Proceedings of 11th IAHR Congress, Leningrad, Russia.

Deng J, Wei WR, Tian Z and Zhang FX (2018) Ski jump hydraulics of leak-floor flip bucket. In 7th International Symposium on Hydraulic Structures, Aachen, Germany (Bung D and Tullis B (eds)). Utah State University, Logan, UT, USA.

Ervine DA and Falvey HT (1987) Behaviour of turbulent water jets in the atmosphere and plunge pools. Proceedings of the Institution of Civil Engineers 83(1): 295-314, https://doi.org/10.1680/iicep. 1987.353 .

Ervine DA, Falvey HT and Withers WA (1997) Pressure fluctuations on plunge pool floors. Journal of Hydraulic Research 35(2): 257-279.

Farinha MLB, Galdeira L and Neves EM (2015) Limit state design approach for the safety evaluation of the foundations of concrete gravity dams. Structure and Infrastructure Engineering 11(10): 1306-1322.

Franzetti S and Tanda MG (1987) Analysis of turbulent pressure fluctuation caused by a circular impinging jet. Proceedings of International Symposium on New Technology, Model Testing and Hydraulic Research, Pune, India. Central Board of Irrigation and Power, New Delhi, India, pp. 85-91.

Hartung F and Häusler E (1973) Scours, stilling basins and downstream protection under free overfall jets at dams. Proceedings of 11th Congress on Large Dams, Madrid, Spain. ICOLD, Paris, France, pp. 39-56.

Heller V (2011) Scale effects in physical hydraulic engineering models Journal of Hydraulic Research 49(3): 293-306.

Heller V, Hager WH and Minor HE (2005) Ski jump hydraulics. Journal of Hydraulic Engineering 131(5): 347-355.

Juon R and Hager WH (2000) Flip bucket without and with deflectors. Journal of Hydraulic Engineering 126(11): 837-845.

Li NW, Liu C, Deng J and Zhang XZ (2012) Theoretical and experimental studies of the flaring gate pier on the surface spillway in a high-arch dam. Journal of Hydrodynamics 24(4): 496-505.

Manso PA, Fiorotto V, Bollaert EFR and Schleiss AJ (2004) Discussion of "Effect of jet content on plunge pool scour" by Stefano Canepa and Willi H. Hager. Journal of Hydraulic Engineering 130(11): 1128-1130.

Manso PA, Bollaert EFR and Schleiss AJ (2008) Evaluation of highvelocity plunging jet-issuing characteristics as a basis for plunge pool analysis. Journal of Hydraulic Research 46(2): $147-157$.

Pardo-Bosch F and Aguado A (2015) Investment priorities for the management of hydraulic structures. Structure and Infrastructure Engineering 11(10): 1338-1351.

Pfister M and Chanson H (2014) Two-phase air-water flows: scale effects in physical modeling. Journal of Hydrodynamics 26(2) 291-298.

Pfister M and Hager WH (2012) Deflector-jets affected by preaerated approach flow. Journal of Hydraulic Research 50(2) 181-191.

Pfister M, Hager WH and Boes RM (2014) Trajectories and air flow features of ski jump-generated jets. Journal of Hydraulic Research 52(3): 336-346.

Puertas J (1994) Criterios hidráulicos para el diseño de cuencos de disipación de energía en presas bóveda convertido libre por coronación. Doctoral thesis, Universidad Politécnica de Cataluña, Barcelona, Spain (in Spanish).

Puertas J and Dolz J (2005) Plunge pool pressures due to a falling rectangular jet. Journal of Hydraulic Engineering 131(5) 404-407

Schmocker L, Pfister M, Hager WH and Minor HE (2008) Aeration characteristics of ski jump jets. Journal of Hydraulic Engineering 134(1): 90-97.

Steiner R, Heller V and Hager WH (2008) Deflector ski jump hydraulics. Journal of Hydraulic Engineering 134(5): 562-571.

Teng $\mathrm{P}$ and Yang J (2018) Modeling and prototype testing of flows over flip-bucket aerators. Journal of Hydraulic Engineering 144(12): 336-346.

Wu JH, Ma F and Yao L (2012) Hydraulic characteristics of slit-type energy dissipaters. Journal of Hydrodynamics 24(6): 883-887.

Wu JH, Wan B, Ma F and Li TC (2015) Flow choking characteristics of slit-type energy dissipaters. Journal of Hydrodynamics 27(1): 159-162.

Xu WL, Deng J, Qu JX, Liu S and Wang W (2004) Experimental investigation on influence of aeration on plane jet scour. Journal of Hydraulic Engineering 130(2): 160-164.

Yang J, Teng P and Zhang $\mathrm{H}$ (2019) Experiments and CFD modeling of high-velocity two-phase flows in a large chute aerator facility. Engineering Applications of Computational Fluid Mechanics 13(1): 48-66.

\section{How can you contribute?}

To discuss this paper, please email up to 500 words to the editor at journals@ice.org.uk. Your contribution will be forwarded to the author(s) for a reply and, if considered appropriate by the editorial board, it will be published as discussion in a future issue of the journal.

Proceedings journals rely entirely on contributions from the civil engineering profession (and allied disciplines). Information about how to submit your paper online is available at www.icevirtuallibrary.com/page/authors, where you will also find detailed author guidelines. 